\title{
Üretim Takip Sistemleri ve Kavramsal Veri Analizi ile Dijital Fabrika Oluşumu
}

\author{
Mustafa Timur ${ }^{1}$, Halil Kılıç ${ }^{2 *}$ \\ ${ }^{1}$ Adnan Menderes Üniversitesi, Mühendislik Fakültesi, Makine Mühendisliği Bölümü, Aydın, Türkiye, (ORCID: 0000-0002-4569-0450), mustafa.timur@ adu.edu.tr \\ 2* Kırklareli Üniversitesi, Teknik Bilimler MYO, Makine Bölümü, Kırklareli, Türkiye, (ORCID: 0000-0001-6182-356X), halil.kilic@klu.edu.tr
}

(İlk Geliş Tarihi 17 Eylül 2021 ve Kabul Tarihi 28 Ocak 2022)

(DOI: $10.31590 /$ ejosat.996760)

ATIF/REFERENCE: Timur, M. \& Kılıç, H. (2022). Üretim Takip Sistemleri ve Kavramsal Veri Analizi ile Dijital Fabrika Oluşumu. Avrupa Bilim ve Teknoloji Dergisi, (33), 285-289.

\section{$\ddot{O} \mathbf{z}$}

Günümüzde hammadde, üretim ve sevkiyat ile ilgili depoların giriş-çıkış işlemlerinin, üretim emirleri ile girdi ve çıktılarının, anlık stok durumlarının, giriş kalite, proses kalite ve final çıkış değerlerinin, bakım süreçlerinin, iş istasyonu kaynak kullanım bilgileri ve iş istasyonu planlamasının yazılım uygulaması üzerinden takip edilmesi üretim verimliliğini ve kapasitesini artırmaktadır. Üretilen ürünün gerçek maliyetinin hesaplanabilmesi için maliyet hesabı yapan yazılımlar ile üretimi anlık takip eden yazılım programlarının entegre çalışması büyük önem arzetmektedir. Bu süreci doğru takip edebilmek için Strateji ve Kalite Yönetim Sistemi ile işletmeye ait formlar, süreçler ve talimatlar gibi kalite dokümanlarının yazılım programları içerisinde iş akış aracı olarak kullanılarak takip edilmesi amaçlanmaktadır. Bu sayede firma içerisindeki temel performans göstergeleri (KPI) takip edilebilecek ve şirket kültürü sanal sisteme taşınmış olacaktır. Ayrıca süreç kurgulamaları sistem üzerinden yapılabilecek ve süreç performans göstergeleri takip edilebilecektir. Bu çalışmada; üretim takip sistemlerinin Endüstri 4.0 ile uyumlu endüstriyel otomasyon ve kavramsal veri analizinin metal tel endüstrisinde faaliyet gösteren kurumsal bir işletmedeki uygulama örneği irdelenmiştir. Uygulama sonucunda, işletmenin üretim maliyetlerinin azaldığı, işgücü verimliliğinin arttığı, fiziksel kaynakların etkin kullanımı ile ürün kalitesinin iyileştiği ve olması gerekenden az da olsa stok denetiminin iyileştiği görülmüştür.

Anahtar Kelimeler: Üretim takip sistemi, Kalite yönetim sistemi, Dijital fabrika, Veri analizi, İşistasyonu.

\section{Digital Factory Formation with Production Tracking Systems and Conceptual Data Analysis}

\begin{abstract}
Today, raw materials, production and shipment related to, the entry and exit processes of all warehouses, with production orders and inputs and outputs input quality, process quality and final output values, maintenance processes, monitoring workstation resource usage information and workstation scheduling through software programs application increases productivity and production capacity. In order to calculate the actual cost of the produced product, software programs that calculate the cost and software programs that monitor the production instantly need to work in an integrated manner. In order to follow this process correctly, it is aimed to follow the Strategy and Quality Management System and quality documents such as forms, processes and instructions belonging to the enterprise by using them as a work flow tool within the software program. In this way, key performance indicators (KPIs) within the company will be monitored and the company culture will be transferred to the virtual system. In addition, process setups can be done through the system and process performance indicators can be followed. In this study; the application example of industrial automation and conceptual data analysis of production tracking systems compatible with Industry 4.0 in a corporate enterprise operating in the metal wire industry has been examined. As a result of the application, it was seen that the production costs of the enterprise decreased, the labor productivity increased, the product quality improved with the effective use of physical resources, and the inventory control became easier, even if it was less than it should be.
\end{abstract}

Keywords: Production tracking system, Quality management system, Digital factory, Data analysis, Work station.

* Sorumlu Yazar: halil.kilic@klu.edu.tr 


\section{Giriş}

Bilgi sistemlerinin temelini oluşturan sayısallaştırmayı ifade eden bir kavram olan dijitalleşme terimi son yıllarda farklı alanlarda sıkça karşımıza çıkmaktadır. Analog verilerin sayısal olarak dönüştürülün veriler, bilgisayar tarafindan işlenerek yönetilebilir duruma gelmiştir. Dijitalleşme, ilk olarak yazılım uygulamalarının kullanılmasıyla süreçlerin otomasyonu olarak işletmelerde ortaya çıkmış ve sonra başta İnternet olmak üzere çeşitli dijital teknolojilerin yardımıyla şirketlerin üretim süreçlerini değiştirmelerine sebep olmuştur. Dijital teknolojilerin gelişmesi ve entegrasyonu sonucu Endüstri 4.0'a geçilmiş ve şirketlerin dijitalleşme süreçleri, üretim süreçlerini, modellerini ve yapılarını da kapsayan dijital dönüşüm olarak adlandırılmaya başlamıştır. Avrupa Komisyonu tarafindan dijital dönüşüm, fiziksel ve dijital sistemlerin entegrasyonu ile yenilikçi iş modellerinin, yeni süreçlerin ve akıllı üretim hizmetlerinin oluşması olarak tanımlanmıştır. Şirketlerin üretim süreçlerinden üretim modellerine, örgütsel yapısından müşteri ilişkilerine kadar kapsamlı bir değişim olarak ifade edilen dijital dönüşüm, köklü bir değişikliğe sebep olduğu için, şirketlerin bu dönüşüm sürecinde başarısızlıkları azaltan, planlayan, işleten ve kontrol eden bir dijital dönüşüm stratejisine ihtiyacı vardır (Matt ve diğer. 2019). Dijital dönüşüm ile ilgili yapılan tanımların ortak noktası, dijital dönüşümün köklü bir değişiklik olduğu ve işletmelerin iş süreçlerinin yanında iş modellerini, müşteri ilişkilerini, iş tanımlarını, çalışan yetkinliklerini ve hatta işletme kültürünü de etkilediğidir (Klein 2020).

Rekabet ettikleri firmalara göre daha avantajlı hale gelebilmeleri için, üretim maliyetlerinde azalmayı, daha fazla üretim esnekliğini ve daha verimli süreçleri sağlamak zorundadır (Timur ve Kılıç 2021). Bunlar hemen hemen her sektörde üretim yapan işletmelerin ortak taleplerinden biridir (Oktaç ve diğer. 2021). Üretimde proses kontrol ve otomasyon sistemleri ile üretim organizasyon sistemleri daha düşük maliyetle yönetilebilir, süreç bilgisi optimize edilebilir ve enerji verimliliği artırılabilir (Edgar Thomas ve Efstratios 2018, Timur ve Kılıç 2021, Türkan 2021). Mühendislik ve operasyonlardaki verimliliği arttırmayı, işletme maliyetlerini azaltmayı ve ürün kalitesini geliştirmeyi amaçlayan işletmeler için endüstriyel otomasyon sistemleri ve dijitalleşme ön plana çıkan en önemli unsurlardır. Dijitalleşme ve akıllı üretim söz konusu olduğunda, dünyanın birçok yerinde üretim yapan işletmeler, genellikle veri kullanılabilirliği ve tutarlılığı ile ilgili temel meseleleri ele almak zorunda kalmaktadır (Monostori 2014). Ardışık birçok farklı sistemden oluşan proseslerin endüstriyel otomasyon ve kontrol sistemleri uygulamaları "Proses Otomasyonu" kavramı olarak adlandırılmaktadır. Kimya, ilaç, demir-çelik, çimento gibi sektörler proses endüstrilerine örnek verilebilir.

Dijital işletmelerde, fiziksel faaliyetleri gözlemlemek, proses iletişimi ve akıllı üretim sistemini amaç edinmektedir. Tamamen birbirine entegre ve endüstriyel ağa bağlı üretim yapan fabrikalar, makineler ve cihazlar, en az manuel müdahale gerektiren akıllı ve kısmen özerk bir şekilde hareket edebilecektir (Gao ve diğer. 2015). Yazılım programları, ürünlerin giriş ve çıkış süreçleri, tablolama, bakım onarım süreci, kalite, depo yönetimi gibi tüm üretim kontrol edilebilir. Makinelerden veri toplanması ve verilerin işlenmesi ile çalışan MES (üretim yönetim sistemi) ile cep telefonu ve/veya bilgisayar ile raporlama yapılabilir, duruş analizi gibi verilerle mobil üzerinden de ulaşım sağlanabilmektedir. Web üzerindende çeşitli tarama motorları aracılığı ile raporlama yapılabilmektedir (Kritikos ve Massonet 2016). Gelişen teknoloji ile işletmeler farklı işlevlerdeki verilerle yoğun etki kalmaktadır. Rekabet ortamı ve serbest pazar hareketliliği fabrikaları yeniden şekillendirmiş ve çözüm arayışı içine sürüklemektedir (Kılıç ve Timur 2021). Dijital dönüşümde Endüstri 4.0, internet ile gerçekleşen iletişimin önemini vurgulamaktadır. Bu sayede büyük veri işleme teknolojilerinin önemi artmaktadır. Teknolojik olarak PC hafiza sistemlerinin de gelişmesi oldukça önemli olmuştur. Akıllı üretim, gerçek zamanlı ve yüksek değerli destek sistemlerini kullanarak, müşteri taleplerine hızlı yanıt veren, enerji ve malzeme kullanımını en aza indiren, sürdürülebilirliği, üretkenliği, yeniliği ve ekonomik rekabeti radikal bir şekilde geliştiren, koordineli ve performans odaklı bir üretim girişimini mümkün kılmaktadır.

$\mathrm{Bu}$ kapsamda işletmeler kaynaklarını etkin kullanabilmek için, ürün ve hizmetlerini, üretim teknolojilerini ve performans göstergelerini rekabet koşullarına uygun olarak senkronize ederek daha verimli üretim ortamları oluşturmalıdır. $\mathrm{Bu}$ çalışmada, metal tel endüstrisinde faaliyet gösteren kurumsal bir işletmenin dijital dönüşüm çerçevesinde, üretim takip sistemlerinin endüstriyel otomasyonu ve kavramsal veri analizi uygulama örneği irdelenmiştir. Bu çalışma ile örnek işletmede bir üretim takip senaryosu belirleyerek, işletmelerin daha kapsamlı ve bütünleyici bir dijital dönüşüm stratejisi geliştirmesine destek olmaktır.

\section{Materyal ve Metot}

Üretim yönetim sistemi olarak ifade edilen MES, üretim sahasındaki anlık veri yönetimini sağlayan ERP (kurumsal kaynak planlaması) ile entegrasyonu gerçekleştiren bir üretim takip sistemi olarak ifade edilmektedir.

\subsection{MES ve ERP İlişkisi}

ERP ve MES sistemleri farklı içeriklere sahiptir. MES işlem anındaki veriyle ilgilenerek, üretimdeki anlık değişimlerin yönetimini sağlar. MES aynı zamanda ERP'nin daha hassas ve doğru verilerle yönetilmesini sağlar. MES ile ERP'nin anlık olarak güncellenmesi sonucu maliyetler ve kaynaklar gözlemlenebilir. MES ve ERP'nin birbirleriyle senkronize çalışma sonucunda üretimde etkili olacağı ifade edilebilir.

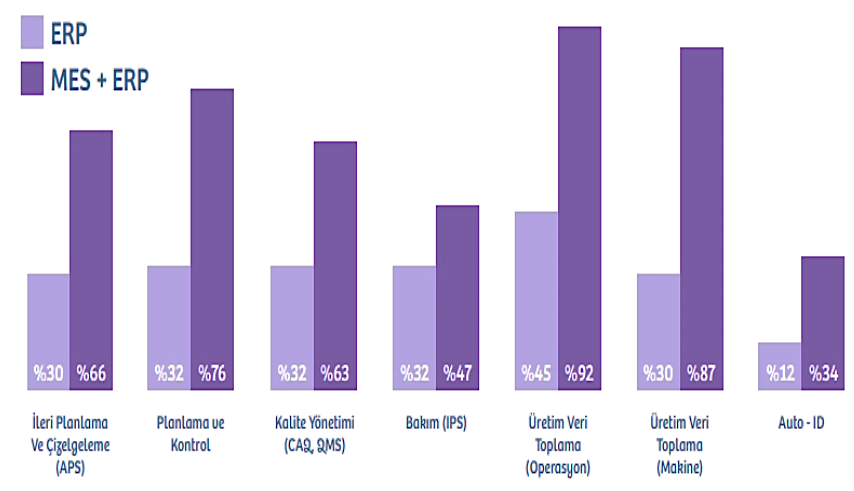

Şekil 1. Entegre MES sisteminin avantajlarl (Figure 1. Advantages of the integrated MES system)

$\mathrm{Bu}$ amaçla MES sisteminde bulunması gereken modüllerin Şekil 2'de görüldüğü gibi ilişkilendirilmesi gerekmektedir. 


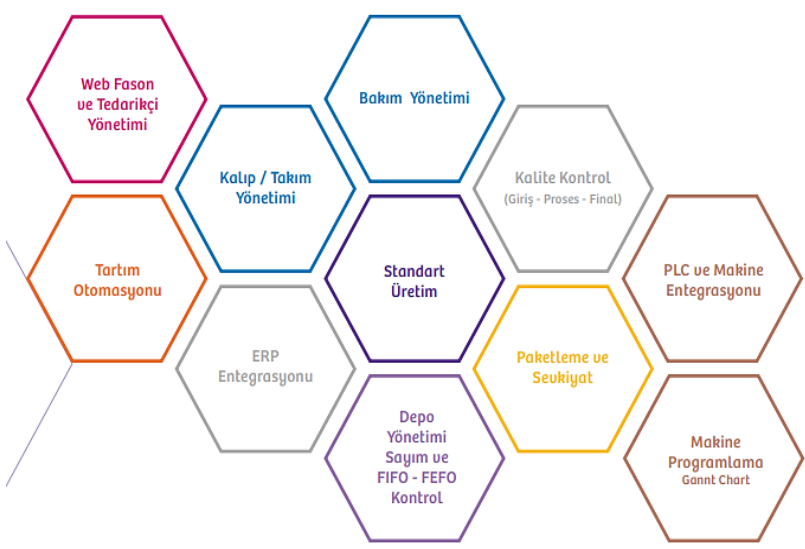

Şekil 2. MES modülleri (Figure 2. MES modules)

\section{2. İş Akışı}

Üretimde meydana gelen bilgi akışını doğru yönetmek çok önemlidir. Bilgi karmaşası ve yönetimi sağlkkl üretim verileri ile çözümlenecektir. Özellikle verimlilik verilerinin değerlendirilmesinde anlık bilginin önemi oldukça yüksek olmaktadır. Şekil 3'te iş akış şeması görülmektedir.

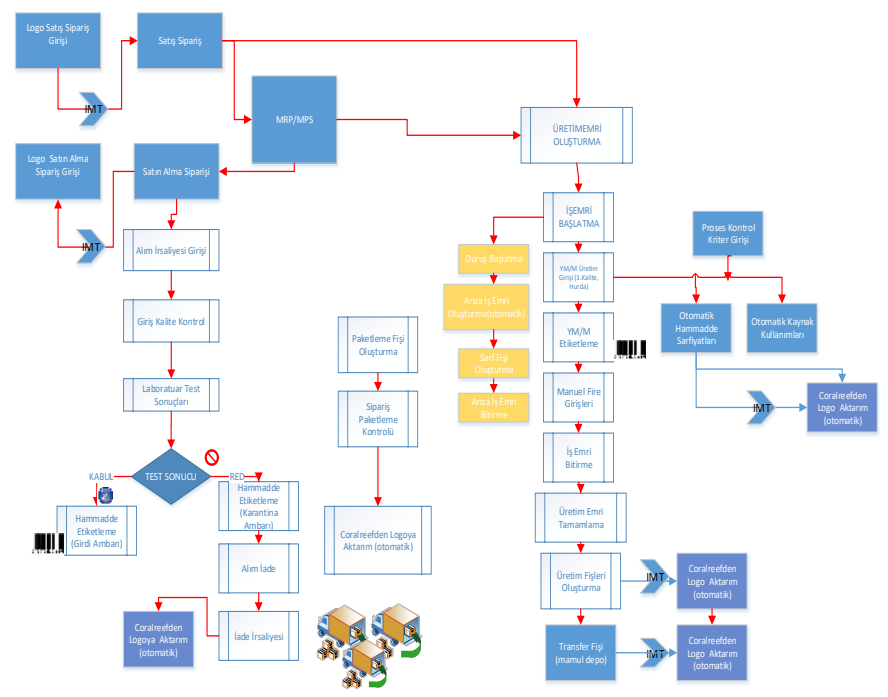

Şekil 3. İşakışs şeması (Figure 3. Work flow chart)

\section{3. Üretim Planlama}

Üretim planlama, üretim sürecinde işletme içerisinde 7/24 çalışan makinelerden elde edilen verilerin işlenmesi olarak tanımlanmaktadır. Bu süreç doğru ve titiz yönetilmelidir. Şekil 4 'te görüldüğü gibi, üretimdeki makinelerden farklı parametre katmanları altında toplanan veriler, CR yazılım programı aracılı̆̆ 1 ile endüstriyel bilgisayarlara aktarılmaktadır.

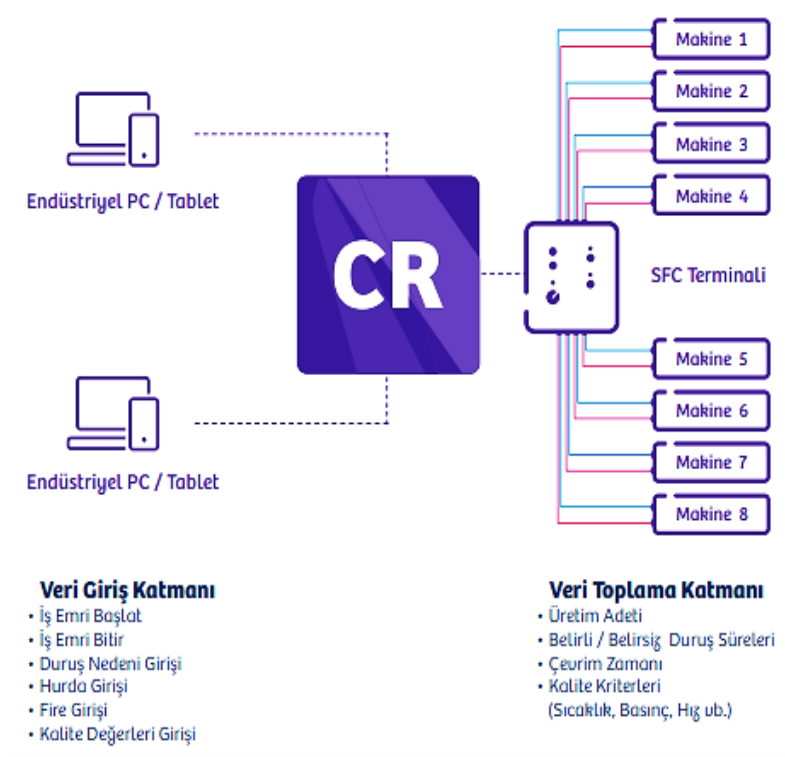

Şekil 4. Üretim veri toplama (Figure 4. Production data acquisition)

Bilgi toplama sürecinde üretim verilerinin sistemde planlı bir şekilde işlenmesi gerekmektedir. Üretim verileri girildikten sonra satış siparişi onayı, sipariş ihtiyaçlarının planlanması ve üretim iş emirlerinin oluşturulması, aylık ve haftalık makine planlaması olarak Şekil 5 'te görüldügü gibi sıralı bir ilerleme ile sağlanmalıdır. Üretimin yapıldığ 1 anda gerçekleşen üretim adet bilgisi ve duruş bilgisi sensörler ile algılanıp sisteme veri girişi yapabilecektir.

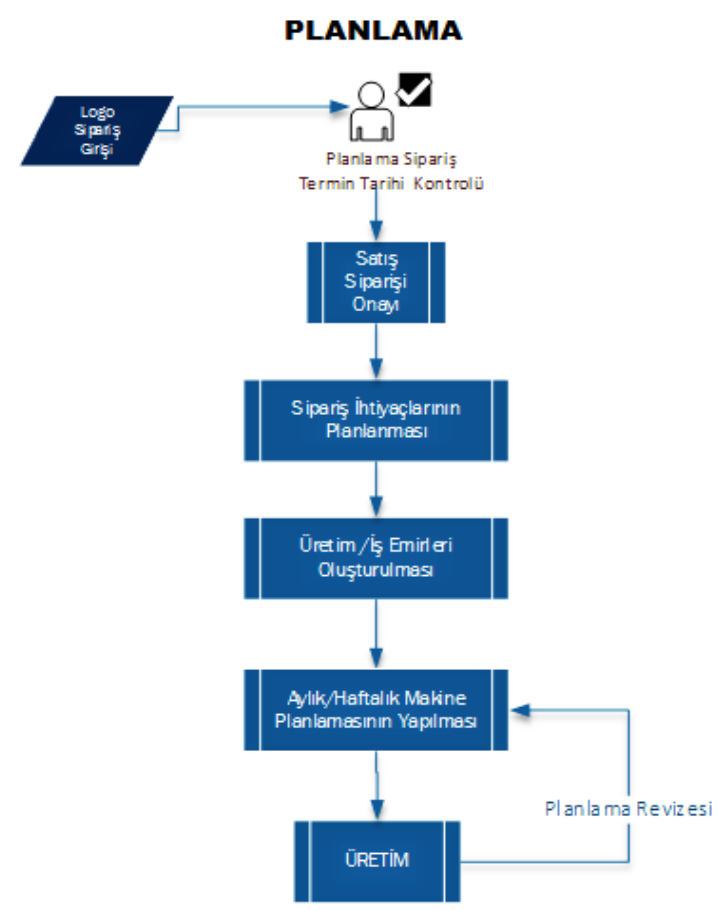

Şekil 5. Planlama akış şeması (Figure 5. Planning flow chart)

\subsection{Bakım Onarım}

Arıza bakım prosesi üretim planı oluşturmada oldukça önemli bir rol oynamaktadır. Üretim yapılan makinelerin istenilen zamanda istenilen miktarda ürün vermesi için bakımlarının zamanında yapılması oldukça önemlidir. $\mathrm{Bu}$ 
sürecin yazılımda planlanması için Şekil 6'da görüldüğü gibi bir iş akışı oluş̧urulmalıdır.

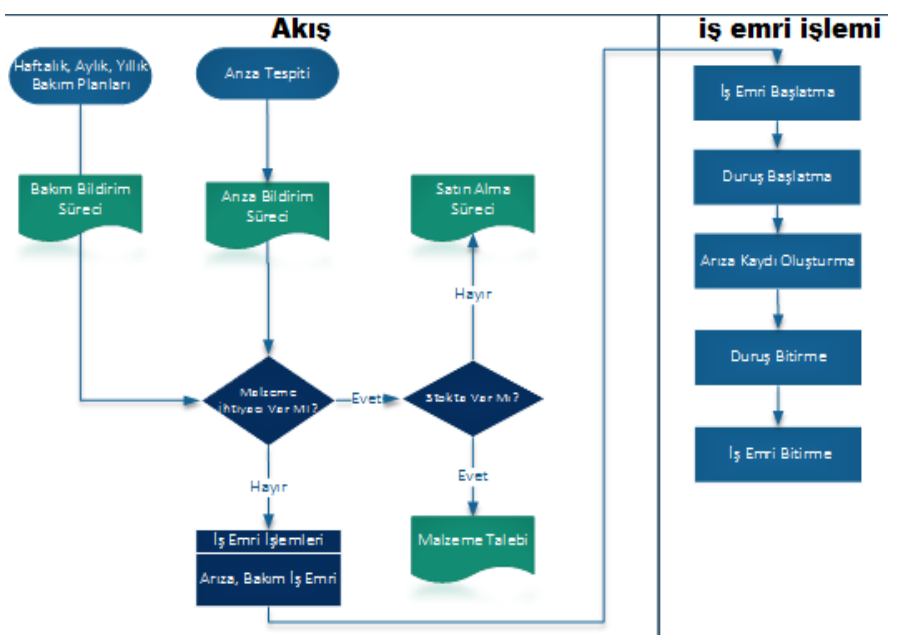

Şekil 6. Makine bakım prosesi (Figure 6. Machine maintenance process)

$\mathrm{Bu}$ süreçte haftalık-aylık-yıllık bakım planları, arıza tespiti, malzeme ihtiyacı ve iş emirleri oluşturup bakımın gerçekleştirilmesi işlemleri sırası ile yapılmaktadır. Modülde bakım ve arızaların tespiti aşağıdaki gibi yürütülmektedir.

- Makinelerdeki hata ve arıza durumunun takibi,

- Bakım onarım uygulama sürelerinin ve gerekli malzemelerin izlenmesi,

- Bakım onarım iş emrinin açılması ve internet yolu ile bilgilendirme,

- Kullanılan malzemelerin bakımı ve takibi,

- Planlı bakım için makinelerin üretimdeki uygun zamanının belirlenmesi,

- Planlı bakım talimatlarının takibi ve işlevlerini içermektedir.

\subsection{Kalite Kontrol}

Yazilım programında operasyonel kalite kontrol süreçlerinin takip edilebildiği sürecin kalite bazında yönetildiği tek modül kullanılmaktadır. Giriş, proses ve final kalite kontrol süreçleri takip edilebilmektedir. Bunlar;

- Malzeme bazında giriş kalite kriteri girişi,

- Malzeme ve tedarikçi bazında giriş kalite kontrol değerleri takibi,

- İstatistiksel giriş değerleri raporlaması,

- Tedarikçi değerlendirme,

- Otomatik kontrol sıklığı bildirimi,

- Otomatik örneklem büyüklüğü bildirimi,

- Numune alma planı takibi,

- Laboratuvar süreci takibi,

- Kalite onayı almamış ürünlerin üretimde kullanılmaması kontrolleri,

- Kalite kriterleri bazında planlanan-gerçekleşen değer analizleri,

- Üretim kriterlerinin izlenebilirliği,

- Proses koşulları standardizasyonu,

- Kalite kontrol sonuçlarının raporlanması gibi fonksiyonları içermektedir.
Üretim, planlama, bakım-onarım ve kalite süreçleri tasarlanıp sisteme girildikten sonra yönetici kurgulanan üretim takip sisteminde yönetici paneli ile tüm makinelerin üretim durumları, duruş bilgileri, üretim emri, stok kartı bilgileri paneli ile üretim eş zamanlı olarak izlenebilecektir. Şekil 7'de üretim takip verilerinin izlenebildiği yönetici ekranı görülmektedir.

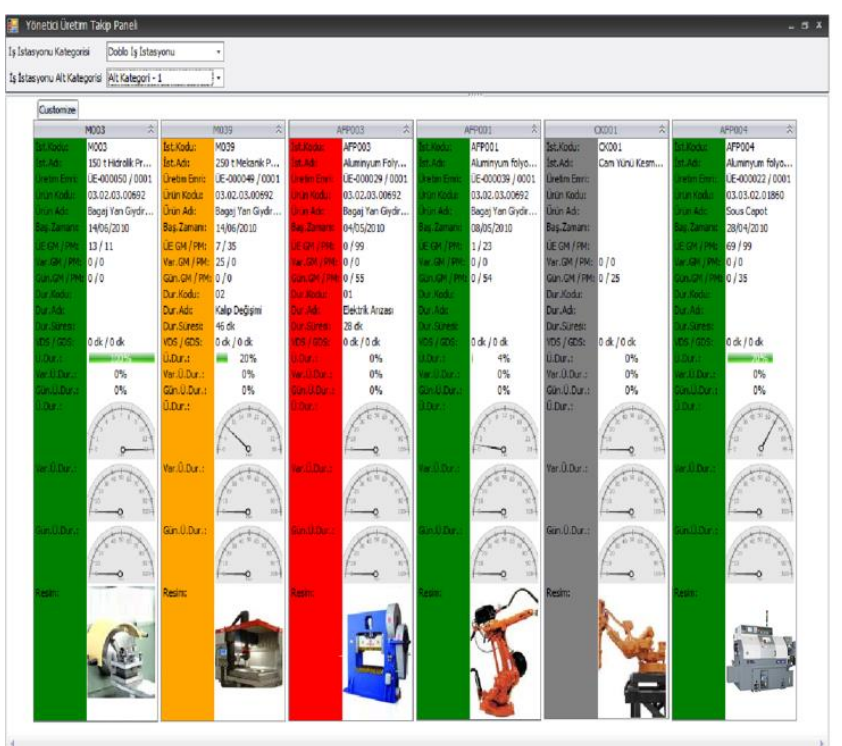

Şekil 7.Yönetici paneli (Figure 7. Admin panel)

\subsection{Formların Oluşturulması}

Çalışanların ya da makinelerin performanslarının kontrol edildiği, formlarla performans göstergelerinin hesaplandığı ve bu formların internet ortamında paylaşıldığı önemli bir yönetim sistemi uygulamasıdır. Şekil 8'de formların oluşturulmasındaki veri giriş akışı görülmektedir.

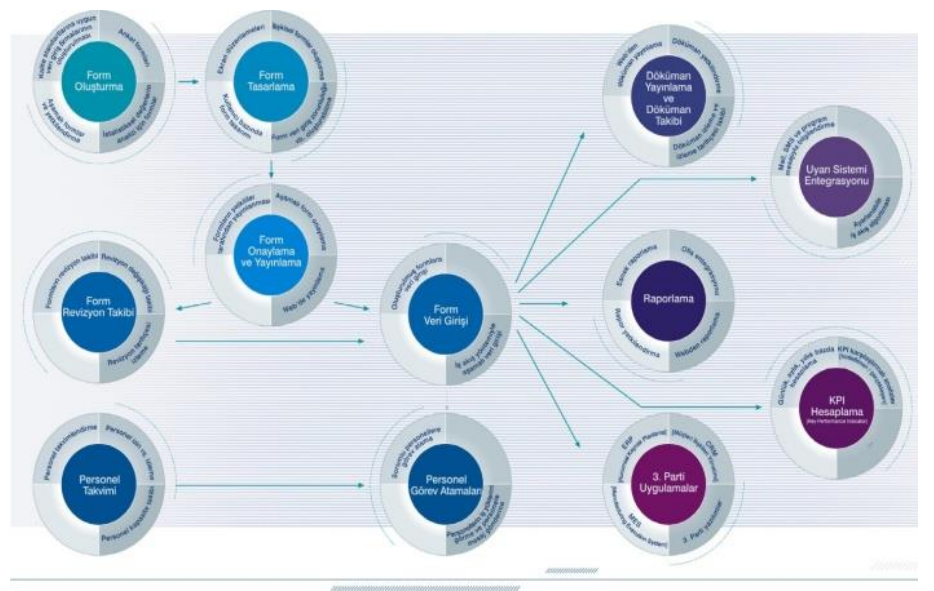

Şekil 8. Form veri girişi (Figure 8. Form data entry)

Program ayrıca raporlama ve analizlerin yapıldığı ve yönetildiği bir modüldür. Bu kısım;

- Kullanıcıya özgü raporlar.

- Tanımlanabilir filtreler ve hesaplanabilir alanlar.

- Office programları ile tam entegrasyon.

- Pivot raporlama.

- Görsel ve grafiksel raporlama.

- View, prosedür ve fonksiyon desteği ile detaylı raporlama.

- Rapor bazında gruplama ve yetkilendirme gibi fonksiyonları içermektedir. 
Özellikle kalite departmanları için büyük kolaylıklar sağlayan iş akışı Şekil 9'de özetlenmiştir.

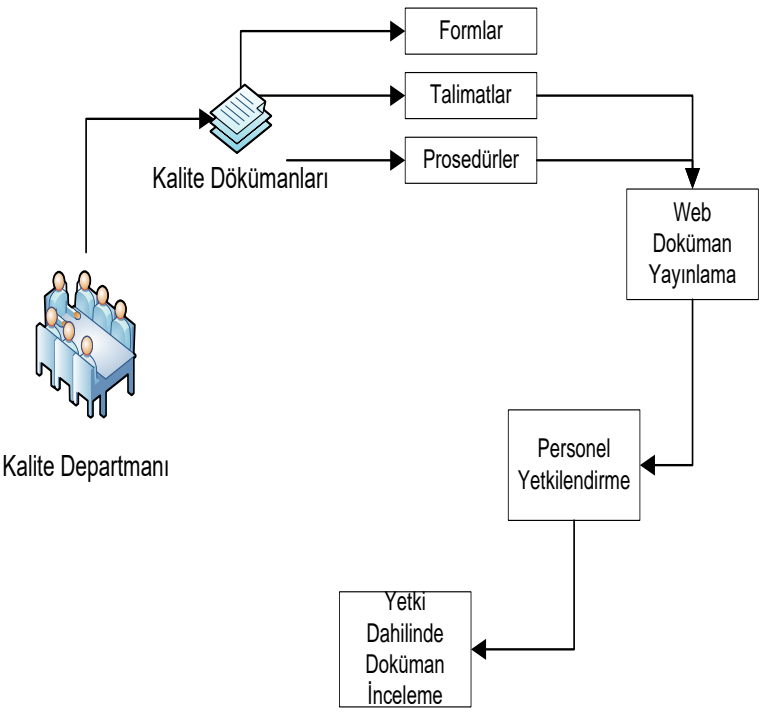

Şekil 9. İs akış formları (Figure 9. Workflow forms)

$\mathrm{Bu}$ özelliklerin firma altyapısına uygulanabilmesi için program eğitimlerinin verilmesi gerekmektedir. $\mathrm{Bu}$ eğitimler aşağıdaki gibi özetlenebilir.

- Bilgi işlem eğitimi (kullanıcılar, roller, parametreler, entegrasyon uygulaması, veritabanı, model değişiklikleri).

- Anahtar kullanıcı tanımlar eğitimi (stok kartları, lot tanımları, cari hesap, çalışan, vardiya, birimler, fabrika, bölüm, işyeri, ambar, stok yeri).

- Anahtar kullanıcı üretim tanımları eğitimi (iş istasyonu, iş istasyonu grubu, operasyon, operasyon grubu, rota, reçete, çalışma takvimi, hata tanımları).

- Anahtar kullanıcı kalite tanımları eğitimi (hammadde giriş kalite tanımları, üretim kalite tanımları).

- Anahtar kullanıcı hammadde kabul eğitimi (alım siparişi, paket/etiket, giriş kalite kontrol, satış siparişinden alım siparişi oluşturma).

- Anahtar kullanıcı üretim eğitimi (makine programlama ekranı, üretim emri açma (manuel ve satış siparişinden), iş emirleri, iş emri satırları, gerçekleşen miktarlar, hammadde kullanımları, fire kayıtları, oluşturulan paket kayıtları, üretim kalite kriterleri girişi).

- Yetkili kullanıcı eğitimi (döküman tasarımı ve kullanımı, form kayıtları ve form veri girişi, cihaz kalibrasyon-bakım bilgileri girişi, takvim işlemleri, personel izin kayıtları, iş akışı, uyarı ikaz işlemleri, DTS sistemi).

\section{Sonuç}

$\mathrm{Bu}$ çalışma, metal tel endüstrisinde üretim yapan kurumsal bir işletmede 24 aylı süreçte uygulamalı olarak gerçekleştirilmiştir. $\mathrm{Bu}$ çalışmanın, imalat sanayinde faaliyet gösteren KOBİ veya büyük işletmelerde üretim planlama ve kontrol faaliyetlerini etkileyen karmaşık durumların ortadan kaldırılarak, üretimde meydana gelen aksamların veya ortaya çıabilecek problemlerin somut delillerle tespit edilmesiyle işletmelere büyük katkı sağlayacağı düşünülmektedir. İşletmelerde üretim takip sisteminin kullanımının, üretim maliyetlerini azalttı̆̆ kaynakların etkin kullanımı ile ürün kalitesini artırdığı ve olması gerekenden az da olsa stok denetimini kolaylaştırdığ 1 görülmüştür. Bu akıllı dijital sistem, covid 19 salgın sürecinde personelin birbiri ile temasını ortadan kaldırmış ve sürecin uzaktan takip edilmesine imkan vererek salgının etkisini azaltmaya olumlu katkı sağladığı düşünülmektedir. Ayrıca üretim sektöründeki işletmelerin dijitalleşme ve verimliliğine yön vermede olumlu katkı sağlayabileceği öngörülmektedir.

\section{Kaynakça}

Edgar, T. F. \& Pistikopoulos, E.N. (2018). Smart manufacturing and energy systems. Computers and Chemical Engineering, $114,130-144$.

Gao, R., Wang, L., Teti, R., Dornfeld, D., Kumara, S., Mori, M. \& Helu, M. (2015). Cloud-enabled prognosis for manufacturing. CIRP Annals - Manufacturing Technology, 64(2), 749-772,

Kılıç, H. \& Timur, M. (2021). Plastik enjeksiyon tezgahlarında vida kırılmasının akustik emisyon yöntemi ile tespit edilmesi, Avrupa Bilim ve Teknoloji Dergisi, 28, 126-129.

Klein, M. (2020). İşletmelerin dijital dönüşüm senaryolarıKavramsal bir model önerisi, Elektronik Sosyal Bilimler Dergisi, 19(74), 997-1019.

Kritikos, K. \& Massonet, P. (2016). An integrated meta-model for cloud application security modelling. Procedia Computer Science, 97, 84-93.

Matt, D. T., Orzes, G., Pedrini, G., Beltrami, M. \& Rauch, E. (2019). Roadmap in eine digitale welt. Zeitschrift für wirtschaftlichen Fabrikbetrieb, 114(9), 576-579.

Monostori, L. (2014). Cyber-physical production systems: Roots, expectations and R\&D challenges. Procedia CIRP, 17, 9-13.

Oktaç, M. T., Timur, M. \& Kılıç, H. (2021). Impact of dehumidification devices on production efficiency in plastic injection, Sakarya University Journal of Science, 25(5), 1129-1135.

Timur, M. \& Kılıç, H. (2021). Analysis of the manufacturing process using polyproplene by plastic injection molding method, European Journal of Science and Technology, 27, 832-836.

Timur, M. \& Kılıç, H. (2021). Endüstride pet şişe üretiminde karşılaşılan problemler ve çözüm önerileri, Düzce Üniversitesi Bilim ve Teknoloji Dergisi, 9(5), 2067-2076.

Türkan, B. (2021). Enjeksiyon edilmiş plastiğin soğutulması işleminin optimizasyon çalışması. Avrupa Bilim ve Teknoloji Dergisi, (31), 801-808. 